\title{
Potential Mechanisms Underlying the Impact of Imaginative Play on Socio-Emotional Development in Childhood*
}

\section{Dorota M. Jankowska}

The Maria Grzegorzewska Pedagogical University E-mail address: dorotamariajankowska@gmail.com

\section{Iwona Omelańczuk}

The Maria Grzegorzewska Pedagogical University E-mail address: iomelanczuk@aps.edu.pl

\section{ARTICLE INFO}

\section{Keywords:}

Children's creativity Imaginative play Socio-emotional competence Preschool children

\section{Article history:}

Received 10 May 2018

Received in revised form 28 August 2018 Accepted 28 August 2018

ISSN: 2354-0036

DOI: 10.1515/ctra-2018-0006

\section{A B S TR A C T}

The aim of this paper is to weigh the empirical and hypothetical evidence to assess the claim that imaginative play supports the acquisition and development of social and emotional competence. We analyse children's play and social skills using a development-based perspective. On this basis, we describe the developmental trajectories of imaginative play and the components of socio-emotional competence during childhood, especially in the pre-school period. In addition, we review the research literature on the possible link between imaginative play and creativity in children, and on how this type of play is predictive of later life creativity. Finally, we discuss hypothetical mechanisms that may account for the relationship between imaginative play and social competence in the preschool years and beyond.

\section{INTRODUCTION}

Creativity, as a characteristic of a person, is a multidimensional, complex construct. Understood in this way, it is composed of many related components, such as creative abilities and certain personality traits (Karwowski \& Jankowska, 2016), intrinsic motivation (Prabhu, Sutton, \& Sauser, 2008), and creative self-beliefs (Beghetto \& Karwowski, 2017). When considering children's creativity (often associated with mini-c creativity, personal creativity, individual creativity), we are usually thinking about personal creative potential, inherent in the learning process (Beghetto \& Kaufman, 2009; Runco, 2004). This concept highlights the personal and developmental aspects of creativity. Children's creativity, defined along these lines, may manifest in creative play, including imaginative play, which is treated as a form of creative activity, the expression of creative potential (Russ, 2014).

\footnotetext{
* This research was supported by grants BSTP 18-16-1 from the The Maria Grzegorzewska Pedagogical University, Poland.
} 
Imaginative play, also known as pretend play or make-believe play ${ }^{1}$, is defined as a combination of two broader theoretical concepts: play and pretense. A number of theorists and researchers who describe pure, spontaneous play do this by pointing to its specific attributes, the so-called play criteria (Smith \& Vollstedt, 1985), mainly: 1) nonliterality, 2) positive affect, 3) intrinsic motivation, and 4) flexibility. Nonliterality refers to the pretend element because behaviours in play usually do not have their normal or literal meaning. Positive affect concerns the enjoyment of play, which can be demonstrated by play signals such as laughter. Intrinsic motivation is associated with voluntariness, which means that play is not constrained by certain external rules or social demands but is done for its own sake. Finally, flexibility sums up the structural characteristics of children's play, as it always has varied forms and content (Krasnor \& Pepler, 1980).

Pretense involves the creation of alternate realities to the real world. There are many definitions of imaginative play activities, but one of the most frequently quoted is Fein's saying that "one thing is playfully treated 'as if' it were something else" (1987, p. 282), referring to symbolic behaviour in this type of play. Theories of pretense representation explain how children acquire the distinction between pretense (non-reality) and reality (e.g., Harris, 2011; Leslie, 1987; Lillard, 2001; Nichols, 2004). These theories and more recent research support the hypothesis that the youngest children's reasoning about pretense is based on their knowledge about reality, as are their beliefs (Fast \& Reet, 2018; Lane, Ronfard, Francioli, \& Harris, 2016; Woolley \& Lillard, 2015; Van de Vondervoort \& Friedman, 2017).

It is generally agreed that play is an activity that supports the acquisition and development of social and emotional skills (Hughes, 1991). Specifically, imaginative play is a natural mode to foster children's expression and a crucial component of healthy development during childhood (e.g. Russ, 2004). Many scholars and researchers emphasise that during imaginative play, young children increase their social competence, emotional maturity and social interactions (e.g. Colwell \& Lindsey, 2005; Lindsey \& Colwell, 2013; Russ, Robins, \& Christiano, 1999). However, there are not many studies in which researchers have tried to understand the mechanisms that underlie the imaginative playsocial and emotional competence link. For this reason, in this paper, we consider more deeply these possible mechanisms. Here, we define socio-emotional development as the emerging competence of young children to "form close and secure adult and peer relationships; experience, regulate, and express emotions in socially and culturally appropriate ways; and explore the environment and learn - all in the context of family, community and culture" (Yates et al., 2008, p. 2).

\footnotetext{
${ }^{1}$ We use the term "imaginative play" because to a greater extent it emphasises the creative, imaginary nature of this kind of child activity.
} 
The purpose of our article is to illustrate how imaginative play lays support for socio-emotional development. First, we describe the patterns of imaginative play and its trajectories of development in childhood. Next, we briefly analyse and review the research literature on the possible link between imaginative play and creativity in children and on how this type of play is predictive of later life creativity. Finally, based on the available data, we analyse the potential impact of imaginative play on social and emotional development in childhood. We end by providing suggestions for future research on this topic.

\section{THE DEVELOPMENTAL TRAJECTORIES OF IMAGINATIVE PLAY}

Developmentally, imaginative play generally begins to appear around 16 months, when children start understanding pretense (Bosco, Friedman, \& Leslie, 2006). There are three basic forms of pretend in play: object substitutions, attributions of properties, and nonexistent or imaginary objects. The earliest form of pretending is object substitution, when children use objects as something else, like a box for a boat. Later, they attribute properties to different objects, like a doll being sick. In the early preschool years, children begin to pretend with invisible objects, in which the pretense occurs entirely in the child's imagination (Leslie, 1987).

The beginning of the development of presymbolic actions is associated with increased sensitivity to the socialised functions of everyday objects. During this period, when children put an empty cup close to their mouth, they try to figure out that a cup is used to drink from. A few months later, the same children may pretend to perform one real action in the imaginary situation, for example, drinking from an empty cup (selfpretend). This form of typical pretending is based on repeated daily activities they have managed to remember. In this initial stage of imaginative play, pretend behaviours are still limited by routine and daily activities (eating, sleeping). Therefore, children are eager to use toys that look quite realistic (e.g., a plastic toy spoon) or real objects as props (Weitzman \& Greenberg, 2002).

Over time (simple pretend, around 18-24 month), children perform imaginative play with a doll or an adult partner. They often imitate adult actions with which they are familiar. For instance, a child may pick up a telephone and pretend to talk in a way the child's mother or father usually does. By about 24 months, most children exhibit a more advanced type of pretending, i.e., a multi-scheme combination comprised of two or more different actions. In the beginning, these actions are related to a familiar routine, such as the next stages of preparing meals and then eating. At this stage, children can also use less realistic objects, as long as they are similar in shape to the real ones. Afterward, less familiar themes appear in the children's play, e.g. they may pretend they are going to the 
doctor's office. Then, children are usually ready to substitute objects that do not resemble the real thing. Sometimes, they try to pretend without any object at all, but role-playing is still mostly a solitary activity (Weitzman \& Greenberg, 2002).

Role play with other children, taking on different roles during this act, is called sociodramatic play or social pretend play. This usually takes the form of an extended social narrative. The players themselves choose an activity to participate in and then define the nature of their interaction in that play. This type of play usually appears between the age of three and five, in the period of the so-called "high season of imaginative play" (Singer \& Singer, 1992, p. 64). "The essence of socio-dramatic play is the spontaneous integration of elements of representation and pretense, reality orientation, organisational skills, reasoning, argumentation and social skills" (Smilansky \& Shefatya, 1990, pp. 27-28). At the beginning, social imaginative play is reproductive but is gradually replaced by more creative forms of play (Weitzman \& Greenberg, 2002). One of the most interesting forms of creative play is the creation of make-believe worlds, often referred to as paracosms (e.g. Taylor, 1999) or imaginative worldplay (e.g. Root-Bernstein, 2014), which can be inhabited by imagined people or beings. Cohen and MacKeith (1991) discerned five typical paracosms based on or invoking fantasy play with (1) toys, (2) particular places and local communities, (3) imagined islands, countries, and their peoples, (4) imagined systems, documents, and languages; and (5) unstructured, idyllic worlds.

Pre-school children also may create imaginary companions (imaginary friends), which may be, for example, non-existent animals, animated objects or people. The creation of an imaginary companion is a common and healthy type of imaginative play. Most children are clear in their understanding that their imaginary friends are not real. Therefore, they distinguish fantasy in play and reality and how they differ (Taylor, 1999; Taylor \& Mottweiler, 2008).

In summary, imaginative play is characterised by children's active engagement with objects, other players and the pretend story. Pretense in play and the involvement of imagination follow the child's developmental timeline. At the beginning, toddlers attribute living characteristics to nonliving objects and transform those from everyday life. During the preschool years, imaginative play is less dependent on props and becomes more abstract and creative. Moreover, in this period, imaginative play becomes more social.

\section{IMAGINATIVE PLAY IN CHILDHOOD AND ADULT CREATIVITY}

Thanks to their natural curiosity, children gain new experiences that become the basis of creative ideas in play. This early exploration of the world may be an expression of children's openness to experiences and willingness to emphasise their own independence (see Typological model of creativity; Karwowski \& Jankowska, 2016). Furthermore, chil- 
dren use fantasy and divergent thinking in the process of creating a context for imaginative play and its plot. They mentally transform toys into a variety of objects and symbols needed in play and generate different scenarios and themes. Therefore, many researchers view imaginative play as the creative elixir of childhood (Russ, 2014), a practice that cultivates divergent thinking abilities (Singer \& Singer, 1992).

There are several reasons why imaginative play may support the development of children's creativity. First, imaginative play is a practice based on making creative associations, which is an important part of divergent thinking. Children generate different story scenarios with different endings. Second, in this type of play, children manipulate symbols and representations of objects, recombining ideas and visual mental images, which is important for creative exploration and transformation abilities. Vygotsky has previously argued that both imagination and the capacity to combine things emerge from children's play: "It is this ability to combine elements to produce a structure, to combine the old in new ways that is the basis of creativity" (Vygotsky, 1930/2004, p. 12). Third, imaginative play is related to the expression and experience of positive affect, which is important in creative activity and creative problem-solving. And, finally, children's play based on imagination develops the cognitive structure to contain, integrate and modulate affect (Russ, 2004).

The authors of a large number of correlational studies have shown that imaginative play is related to different aspects of creativity, including divergent thinking, independent of intelligence (e.g., Delvecchio, Riso, Li, Lis, \& Mazzeschi, 2016; Fisher, 1992; Russ \& Grossman-McKee, 1990; Russ et al., 1999; Russ \& Schafer, 2006), flexible problem solving (Russ, 2004) and creative storytelling, and independent verbal ability (Hoffmann \& Russ, 2012). Also, experimental studies suggest that play might have a positive effect on the development of divergent thinking abilities in childhood (e.g. Dansky, 1980; Dansky \& Silverman, 1973; Li, 1978; Udwin, 1983). The authors of these studies have demonstrated that educational and school-based interventions can be effective in fostering imaginative play skills and creative abilities. In one of these studies (Udwin, 1983), in which pre-school children participated, an imaginative play intervention involved modelling, imagination, and object transformations. The intervention group showed improvement in divergent thinking, imaginative play, and verbal fluency at four weeks post experiment. However, it should be noted that the primary limitations of most of these studies are their low power to detect group differences due to their small sample size, correlational studies discussed as causal, experimenter bias, and unsound statistical practices (Lillard et al., 2013).

Several studies (e.g., Clark, Griffing, \& Johnson, 1989; Mullineaux \& Dilalla, 2009; Russ et al., 1999; Wallace \& Russ, 2015) aimed to investigate the predictive power of im- 
aginative play in creativity. For example, in a four-year follow-up study, Russ and colleagues (1999) established a significant correlation between fluency of divergent thinking and early imaginative play.

In summary, relationships between imaginative play and other forms of children's creativity, such as divergent thinking and creative storytelling skills, have been empirically demonstrated. Thus, play, combined with the use of fantasy, fosters problem solving and creative thinking in children. Furthermore, imaginative play in childhood may be one of the predictors of adult creativity. It is possible that imaginative play interventions during early childhood can lead to improved creative abilities in adolescence and adulthood.

\section{SOCIAL AND EMOTIONAL DEVELOPMENT DURING THE PRESCHOOL YEARS}

The analysis of the social competence necessary to build relationships with peers has a long and rich history. At the beginning of the 20th century, many works on this topic appeared and were discussed at the time by Bühler (1931, see: Rubin, Bukowski, \& Parker, 1998 ) in the first chapter of her guidebook devoted to peer relations. Nowadays, social competence is understood as the condition of possessing the social, emotional and intellectual skills and behaviours needed to succeed as a member of society. They are, therefore, a set of constantly developing skills and knowledge which contribute to effective interactions with the environment and determine peer acceptance (Krasnor, 1997). Social interactions are a prerequisite for acquiring and developing social competence. At the same time, contacts with other people cause emotions, as well as being triggered by emotions. For this reason, social and emotional development are closely related (Halberstadt, Denham, \& Dunsmore, 2001). The social and emotional skills that determine effectiveness when interacting with other people are: correct communicating, reading and naming of emotional states, and perspective taking (the ability to recognise and name internal states and their causes), affect and behaviour regulation, and social problem-solving empathy (Halberstadt et al., 2001; Rubin et al., 1998).

In early childhood, social and emotional development are based on various social contacts made at home and kindergarten. The basis of this development is understanding emotions: the ability to name them, their correct interpretation, and an adequate response to their own and others' emotions. The majority of three-year-olds can recognise and name basic emotional states based on facial expressions. Usually, a year later, they are able to name some of the complex emotions such as surprise, jealousy, pride or shame (e.g., Wellman, Harris, Banerjee, \& Sinclair, 1995). Moreover, children of this age have a basic emotional situation knowledge which allows them to correctly interpret why another person felt in a certain way at that time; however, this occurs only if they have been 
able to experience it in a previously observed situation (Gross \& Ballif, 1991). At the same time, the causes of people's emotional states are often explained by reference to external and not internal factors, such as thoughts, expectations, preferences, beliefs or personality traits (Dunn, Brown, Slomkowski, Tesla, \& Youngblade, 1991). At the end of the pre-school period, most children are already able to correctly recognise and name emotions, and to explain causes and complex emotions (Gross \& Ballif, 1991). Children of this age also understand that those emotions are affected not only by the objective characteristics of the situation, but also by internal states, for example, one's desires and beliefs about a specific event (Lagattuta, Wellman, \& Flavell, 1997). Greater proficiency in identifying emotional states is associated with the ability to make inferences about the states of mind of other people (Hughes \& Dunn, 1998). The ability to comprehend others' thoughts, imageries, desires, expectations, beliefs and needs makes it possible to read the intentions of their actions, which translates into a better understanding of the causes of their behaviours and effective ways for predicting them. Researchers call this ability the theory of mind (ToM) (Baron-Cohen, 2000). With age, skills in this area increase, and the biggest qualitative change occurs between three and four years of age. Four-year-olds understand that different people may have a different state of knowledge about the same event (Wellman, Cross, \& Watson, 2001). Usually, a year later, they become aware of the fact that people's behaviour depends on their beliefs, which are not always in line with reality (Wimmer \& Perner, 1983). Empathy is a multidimensional concept defined as the ability to infer about states of mind and purposeful action towards another human being. Most often, it is identified with prosocial behaviours (Smith, 2006), and that is why it is treated as a significant element of interpersonal communication. Its development is closely related with ToM, and the first manifestations of prosocial behaviours can be observed between two and three years of age (Denham, 1986).

Another important social competence is emotion and behaviour regulation, which is based on the conscious inhibition, strengthening, maintenance and modulation of emotional or behavioural stimulation in order to achieve the intended goal. Between three and six years of age, significant developmental changes are observed in children's ability to delay, mitigate, refrain from, or completely change their response to opposition (Gerstadt, Hong, \& Diamond, 1994). They are associated with children's gradual acquisition of knowledge about the rules for expressing emotions that are accepted in their environment. From an early age, children learn not only how to verbally say 'thank you' for a gift received, but also how to replace their disappointment with a perceived satisfaction when they simply do not like the gift (Saarni, 1984). Emotion regulation, especially anger man- 
agement, is associated with the ability to conform to the standards of socially appropriate behaviours within a context populated by both peers and adults (Gilliom, Shaw, Beck, Schonberg, \& Lukon, 2002), high-quality social functioning (Eisenberg, Fabes, Guthrie, \& Reiser, 2000), and the ability to read other people's mental states (Carlson \& Moses, 2001). Also, it relates to problem solving in a conflict situation with peers. There are two strategies used by children in problem solving: prosocial and antisocial. For the development of constructive problem-solving strategies, it is important to have the ability to generate alternative solutions and flexibility in the choices, and a consideration of the consequences of one's social acts for oneself and others. Non-constructive strategies involve impulsive involvement in behaviours such as physical and mental abuse, distracting actions and avoidant behaviour, doing nothing, denying, or cognitive avoidance. Children with a low ability to inhibit their active stimulation are more likely to cope in a nonconstructive way (Eisenberg et al., 2000). With the increase of emotion and behaviour regulation, the overall number of aggressive behaviours by children drops, and their irritability and frustration decreases (Rothbart, Ahadi, \& Hershey, 1993). Also, a greater ability to infer other people's emotional and mental states results in the more frequent use of relevant interpersonal problem-solving and rarer interpersonal force (Capage \& Watson, 2001).

There are a number of factors related to socio-emotional competence which refer to functioning in a peer group, including the reading, interpretation and appropriate reaction to other people's emotions, prosocial behaviours, connected with the ability to share, antisocial behaviours, mainly aggression, and the ability to solve interpersonal problems (Newcomb, Bukowski, \& Pattee, 1993).

Preschool children purposely use the names of emotions in order to influence other's behaviour and win their affection (Wellman et al., 1995). They respond adequately to the emotions expressed by their peers, especially the positive ones. In such cases, they usually reciprocate or reinforce them verbally or physically, e.g., by hugging (Denham, 1986). If a peer expresses negative emotions, children are no longer as adequate and consistent in their responses (Camras, 1977). Recent studies have shown that the incorrect identification of other people's emotions is connected with lower popularity among peers (e.g., Denham, Mckinley, Couchoud, \& Holt, 1990). The ability to appropriately identify and interpret ambivalent emotions, which expresses a high level of emotional competence, relates to positive emotions between peers (Brown \& Dunn, 1996). Taken together, these studies suggest that both positive and negative high-intensity emotional behaviour play a role in determining concurrent peer status.

It has also been claimed that children who understand other children's positions are sympathetic, helpful, not insulting or bullying, nurturing, altruistic and likely to share, more 
liked by their peers, and have more friends in general (Denham et al., 1990). The ability to control one's own emotions and behaviours, as well as constructive coping in conflict situations, is also positively related to one's sociometric position in a peer group (Eisenberg et al., 2000). On the contrary, non-constructive, social problem-solving contributes to less peer acceptance (Denham et al., 1990; Fabes \& Eisenberg, 1992). More frequent antisocial problem solving is associated with more problems in behaviour, including aggressive behaviours initiated by the child (Eisenberg et al., 2000) which also results in a decline in his/her acceptance and popularity among peers (Arsenio, Cooperman, \& Lover, 2000). Interestingly, in the case of boys, the decrease in popularity is influenced by fighting and aggressive behaviour, whereas in the case of girls, by being sneaky and not sharing with others (Keane \& Calkins, 2004).

Summarising across these studies, almost as soon as children are able to talk, they begin to report their own and other people's feelings and they attribute various emotions to nonhumans, for example, dolls or stuffed animals. Over the years, children's emotional vocabulary expands, their discussion of hypothetical emotions gets underway and the complexity of their emotional utterances increases. Competence such as inferences about the internal states of other people, the ability to control emotional and behavioural arousal or prosocial problem solving are intensively developed. From a developmental perspective, each of them affects effective social functioning and individual differences in the development level of certain skills and may reflect the children's peer social status.

\section{UNDERSTANDING THE IMPACT OF IMAGINATIVE PLAY ON SOCIAL AND EMOTIONAL DEVELOPMENT}

In imaginative play, children can experience different emotions and assess feelings they experience, and by generalising these assessments to the emotional and mental experiences of others, they build social scenarios of behaviour in specific situational contexts in their minds. This also provides the opportunity to experience a variety of emotions and their expression. Imaginative play creates many opportunities for taking on the perspective of other people and getting into the emotions of the characters played. The greater possibility of experiencing and expressing various emotions during imaginative play and getting into the emotions of the characters played is reflected in the children's higher knowledge about emotions in non-play social situations (Lindsey \& Colwell, 2013). It has been demonstrated that the quality of imagination during imaginative play is connected with the understanding of the emotions of other people, although it is not related to the ability to describe one's own emotional experiences (Seja \& Russ, 1999). Thus, it seems that a higher quality of imagination in play allows us to imagine what a different person may feel or think, and playing a role in imaginative play requires an understanding of the 
emotions and mental states of the character played. This promotes the learning and understanding of the emotional and mental states of other participants in the game, but it does not require the identification of one's own states.

Children with a higher level of divergent thinking are characterised by more frequent and more diverse expressions of affect (Seja-Kaugars \& Russ, 2009), and a greater variety of emotional expressions during imaginative play is associated with a higher positive mood in daily life (Fiorelli \& Russ, 2012). This may mean that the more frequent involvement in imaginative play of children with higher divergent thinking provides them with better coping abilities and higher subjective well-being. Imaginative play also offers the opportunity to experience a large range of emotions and probably allows negative and traumatic experiences to be worked on symbolically, thus freeing the child from them.

Children who participate more often in imaginative forms of play are characterised by a better understanding of other people's feelings and beliefs (Taylor \& Carlson, 1997; Youngblade \& Dunn, 1995) and higher leadership skills in play, which are also related to more frequent initiation and creation (Saracho, 1992). This may be due to the fact that during joint imaginative play, children must share the world they have imagined, recognise and understand that their partner in play is pretending, and also pretend to follow the expectations of other participants while playing, according to the established conventions or roles. A better understanding of other people's mental states and their perspectives makes it easier for children to communicate their ideas more effectively, but also to avoid conflicts, providing more opportunities for cooperation while playing. These children are more open to discussion with others about the play and take into account the suggestions of other participants more often. In addition, their attempts to contact and communicate with others are, in most cases, successful. They are also less likely to impose their will by threatening, insulting, protesting or rejecting, or ignoring the suggestions of other participants in the game. They also try to prohibit others' activities less often (Dunn \& Cutting, 2001). It seems, therefore, that children who are more aware of the fact that their play partners may have different beliefs about the creation and explanation of the world are more active in creating and explaining this world, which also translates into their decisive influence on the division of roles in play and its course (Astington \& Jenkins, 1995). However, the problem of whether the ability to understand the mental states of others is a necessary condition for, or the consequence of, imaginative play remains unanswered (Bailey, 2002).

In play, children not only acquire and practice new skills, but also have the opportunity to try different variants of solutions to particular social problems. This allows them to assess the effectiveness of individual solutions and their social consequences (Peter, 2003). Children also face the challenge of creating and complying with established rules, 
negotiating the roles they play, and agreeing on the course of the play itself (Bailey, 2002). And although imaginative play favours a better understanding of the other person's perspective, a clearer presentation of their own point of view, and the generation of alternative solutions that are satisfactory for all parties to the conflict, it engages more participants than other types of play, and therefore, potentially generates more conflict situations (Connolly, Doyle, \& Reznick, 1988). Moreover, while playing, not all the ideas of a particular child are realised, and not all children play the desired roles. Thus, children must not only try to incorporate their ideas into common activities, but also deal with negative emotions if they are rejected. Interestingly, children who more often engage in imaginative play are more liked (Colwell \& Lindsey, 2005) and are characterised by higher friendly enactment and sociability (Howes \& Matheson, 1992). The higher abilities of these children to control the behaviour of others (Connolly et al., 1988) and the lower difficulties in peer contacts (Howes \& Matheson, 1992) are possible thanks to their higher social competence and leadership skills, so that these children are likely to act in a consensus manner, avoiding arbitrary impositions of their own will (Saracho, 1992).

According to some researchers (e.g. Howes \& Matheson, 1992), more frequent involvement in imaginative play is associated with greater instrumental aggression. Others (e.g. Fung \& Cheng, 2015) have not confirmed that this type of play affects the number of disruptive behaviours, and yet others point to less internalising behaviour problems for children who are more likely to engage in imaginative play (Seja-Kaugars \& Russ, 2009). The reduction of internalising behaviour problems in children more often involved in imaginative play may result from the fact that this type of play provides greater opportunities for the expression of various emotions, including negative ones, which allows them to be released, and as a result, can lead to a decrease in internalising behaviour problems.

Within this context, the relationship between imaginary play and aggressive behaviour also seems to be interesting. A higher level of creativity in imaginative play and fantasy stories in children favours exploring, mastering and diffusing the violence and aggression in symbolic activities in an imaginary world, not in the real world (Bacigalupa \& Wright, 2009). These dependencies can be explained by referring to a developmental view. Aggression expressed in imaginative play and fantasy stories gives the opportunity to overcome the child's concerns about the convictions arising from engaging in specific settings in a world outside of play, trying out conflicting ideas, and experimenting with solutions that are not accepted by the child's environment, that children have come across on TV, a book, a computer game or in their own life. On the other hand, some researchers dispute these claims (e.g. Levin \& Carlsson-Paige, 2006), pointing to the threat of in- 
creased interest in aggressive solutions in the real world in those children who try out certain symbolic actions in imaginative play or fantasy stories. However, the confirmation of these assumptions may be found in analyses indicating a higher level of verbal aggression and physical aggression in more creative children, especially those characterised by such dimensions of verbal and creative thinking as fluency, originality and flexibility (Tacher \& Readdick, 2006). It should also be noted here that children who manage more fantasy and high imagination in their play more often deal with stressful situations (Russ et al., 1999). Furthermore, a higher level of emotion regulation is characterised by less creative children, with a higher level of divergent thinking, fluency, flexibility and originality, which are more often involved in imaginative play (Hoffman \& Russ, 2012), although the significance of these relationships may be the quality rather than quantity of this play (Galyer \& Evans, 2001). Thus, a higher level of creativity in children and more frequent involvement in imaginative play are associated with better regulation of arousal and the flexible use of more diverse and sophisticated ways of dealing with emergency situations, even if they involve some level of aggression. For this reason, a more creative child, in a conflict or threat situation, is more likely to first engage in verbal threats and not physical aggression. The type of reaction chosen by this child will be the most optimal solution considering success and the costs incurred (Lazarus, 1991). However, because more creative children are able to generate many variants of reactions in a given situation and have higher skills of purposeful modulation, this can encourage them to use aggressive behaviours to achieve success. However, the existing data on the relationship between creativity and aggressive behaviour are not conclusive, and this requires further exploration.

An interesting question, which has yet to be answered, is the issue of whether higher social and emotional skills in children are reflected in their empathic behaviour. The ability to properly read the emotional and mental states of others is a prerequisite for empathic compassion. Some analyses indicate that children with a higher level of social skills during imaginative play are more helpful and have less disrupting behaviours during play (e.g. Gagnon \& Nagle, 2004). On the other hand, children who are active participants and have higher social competence during imaginative play do not display more empathic behaviour towards other people (Astington \& Jenkins, 1995). The explanation for these discrepancies may be the independence of understanding the emotions and mental states of other people and their own behaviour towards these people. Perhaps behaviour such as comforting another person when s/he cries does not require empathic compassion, but a reaction according to the learned behaviours for a given situation. Thus, a better understanding of other people's emotional states is not synonymous with 
providing help or support, as it also facilitates opposing behaviours, such as deliberately harming or cheating another person (Astington, 1993).

Although the quoted analyses indicate links between creativity or imaginative play and social and emotional competence, there is no consensus among researchers on this issue. However, some of them indicate that it does not matter how much time devoted in general to playing is used by children on imaginative play (Astington \& Jenkins, 1995; Fung \& Cheng, 2015). At the same time, higher social competence in children who are more often involved in imaginative play is influenced by the sex of the play partners, but this effect is visible only in the case of boys. Higher social competence is characterised by those boys who spend more time in imaginative play with other boys, not girls. In the case of girls, higher social competence is associated with more frequent involvement in imaginative play regardless of the sex of the play partners (Colwell \& Lindsey, 2005). Still, other researchers (e.g. Swindells \& Stagnitti, 2006) have not confirmed that imaginative play is related to social-emotional competence.

In summary, imaginative play allows children to look at the play situation from the perspective of the characters played in the game and imagine what emotions can appear in it. This experience helps children to look at social situations through the eyes of others, which is associated with higher effectiveness in interacting with other people. The higher level of creativity reflected in surprising and original solutions to social situations, including conflictual and stressful ones, allows more frequent success in coping with interpersonal problems. In addition, when there is a higher level of quality of imagination during imaginative play, children not only have many opportunities to imagine the whole range of celebrating other people, but also to overcome their own negative emotions in a safe situation, which affects the use of subjective well-being and reduces the risk of internalising behaviour problems in children. Nevertheless, there are still many uncertainties about the links between imaginative play and social competence, such as the question of whether this type of play affects the formation of social competence or appears as a result of the shaping of a certain level of this competence.

\section{CONCLUSION}

The authors of most of the theoretical and empirical work highlight the link between imaginative play and socio-emotional competence. However, only a limited literature has undertaken the topic of the impact of the mechanism of imaginative play on socio-emotional development. This special type of social play appears to provide a developmental framework within which mature social interactions can occur and socio-emotional competencies may be acquired. So far, the studies on the relationship between imaginative play 
and social competence have been primarily correlational in nature (Lillard et al., 2013). For this reason, more research is needed to investigate the hypothetical impact of mechanisms of imaginative play on socio-emotional development in childhood. First, these new studies should provide a more natural context of imaginative play, which allows spontaneous play wherein children have a wide range of pretending activities. Also, in the description and analysis of the development of social competence, such research should strive to make full use of quasi-observational methods that relate to behaviour in natural, everyday situations involving peers and adults. This will ensure the ecological validity of the conducted research, and in the longer term, it will also allow conclusions to be drawn about the potential impact of mechanisms of imagination on the social and emotional development of children.

\section{REFERENCES}

Arsenio, W. F., Cooperman, S., \& Lover, A. (2000). Affective predictors of preschoolers aggression and peer acceptance: Direct and indirect effects. Developmental Psychology, 36(4), 438-448.

Astington, J. W. (1993). The child's discovery of the mind. Cambridge, MA: Harvard Astington, J. W., \& Jenkins, J. M. (1995). Theory of mind development and social understanding. Cognition \& Emotion, 9(2-3), 151-165.

Bacigalupa, C., \& Wright, C. (2009). “And Then a Huge, Huge Giant Grabbed Me!” Aggression in Children's Stories. Early Childhood Research and Practice 11(2), 1-15.

Bailey, R. (2002). Playing Social Chess: Children's play and social intelligence. Early Years: An International Research Journal, 22(2), 163-173.

Baron-Cohen, S. (2000). Theory of mind and autism: A review. Autism International Review of Research in Mental Retardation, 23, 169-184.

Beghetto, R. A., \& Karwowski, M. (2017). Toward untangling creative self-beliefs. In M. Karwowski \& J. C. Kaufman (Eds.), Explorations in creativity research. The creative self: Effect of beliefs, self-efficacy, mindset, and identity (pp. 3-22). San Diego, CA, US: Elsevier Academic Press.

Beghetto, R. A., \& Kaufman, J. C. (2009). Intellectual estuaries: Connecting learning and creativity in programs of advanced academics. Journal of Advanced Academics, 20, 296-324.

Bosco, F. M., Friedman, O., \& Leslie, A. M. (2006). Recognition of pretend and real actions in play by 1- and 2-year-olds: Early success and why they fail. Cognitive Development, 21(1), 3-10.

Brown, J. R., \& Dunn, J. (1996). Continuities in Emotion Understanding from Three to Six Years. Child Development, 67(3), 789-802. 
Camras, L. A. (1977). Facial Expressions Used by Children in a Conflict Situation. Child Development, 48(4), 1431-1435.

Capage, L., \& Watson, A. C. (2001). Individual Differences in Theory of Mind, Aggressive Behavior, and Social Skills In Young Children. Early Education \& Development, 12(4), 613-628.

Carlson, S. M., \& Moses, L. J. (2001). Individual Differences in Inhibitory Control and Childrens Theory of Mind. Child Development, 72(4), 1032-1053.

Clark, P. M., Griffing, P. S., \& Johnson, L. G. (1989). Symbolic play and ideational fluency as aspects of the evolving divergent cognitive style in young children. Early Child Development and Care, 51(1), 77-88.

Cohen, D., \& MacKeith, S. (1991). The development of imagination: The private worlds of childhood. London: Routledge.

Colwell, M. J., \& Lindsey, E. W. (2005). Preschool Children's Pretend and Physical Play and Sex of Play Partner: Connections to Peer Competence. Sex Roles, 52(7-8), 497-509.

Connolly, J. A., Doyle, A. B., \& Reznick, E. (1988). Social pretend play and social interaction in preschoolers. Journal of Applied Developmental Psychology, 9(3), 301-313.

Dansky, J. (1980). Make-believe: A mediator of the relationship between play and associative fluency. Child Development, 51(2), 576 -579.

Dansky, J. L., \& Silverman, I. W. (1973). Effects of play on associative fluency in preschool-aged children. Developmental Psychology, 9(1), 38-43.

Delvecchio, E., Riso, D. D., Li, J., Lis, A., \& Mazzeschi, C. (2016). Affect in Play ScalePreschool Version: Validation on a Sample of School Age Italian Children. Journal of Child and Family Studies, 25(12), 3523-3536.

Denham, S. A. (1986). Social Cognition, Prosocial Behavior, and Emotion in Preschoolers: Contextual Validation. Child Development, 57(1), 194-201.

Denham, S. A., Mckinley, M., Couchoud, E. A., \& Holt, R. (1990). Emotional and Behavioral Predictors of Preschool Peer Ratings. Child Development, 61(4), 1145-1152.

Dunn, J., Brown, J., Slomkowski, C., Tesla, C., \& Youngblade, L. (1991). Young Childrens Understanding of Other Peoples Feelings and Beliefs: Individual Differences and Their Antecedents. Child Development, 62(6), 1352-1366.

Dunn, J., \& Cutting, A. L. (2001). Understanding Others, and Individual Differences in Friendship Interactions in Young Children. Social Development, 8(2), 201-219.

Eisenberg, N., Fabes, R. A., Guthrie, I. K., \& Reiser, M. (2000). Dispositional emotionality and regulation: Their role in predicting quality of social functioning. Journal of Personality and Social Psychology, 78(1), 136-157. 
Fabes, R. A., \& Eisenberg, N. (1992). Young Childrens Coping with Interpersonal Anger. Child Development, 63(1), 116-128.

Fast, A. A., \& Reet, J. V. (2018). Preschool children transfer real-world moral reasoning into pretense. Cognitive Development, 45, 40-47.

Fein, G. G. (1987). Pretend play: Creativity and consciousness. In D. Görlitz \& J. F. Wohlwill (Eds.), Child psychology. Curiosity, imagination, and play: On the development of spontaneous cognitive motivational processes (pp. 281-304). Hillsdale, NJ: Lawrence Erlbaum Associates.

Fiorelli, J. A., \& Russ, S. W. (2012). Pretend play, coping, and subjective well-being in children. A follow-up study. American Journal of Play, 5(1), 81-103.

Fisher, E. P. (1992). The impact of play on development: A meta-analysis. Play \& Culture, 5(2), $159-181$.

Fung, W., \& Cheng, R. W. (2015). Effect of School Pretend Play on Preschoolers' Social Competence in Peer Interactions: Gender as a Potential Moderator. Early Childhood Education Journal, 45(1), 35-42.

Gagnon, S. G., \& Nagle, R. J. (2004). Relationships between peer interactive play and social competence in at-risk preschool children. Psychology in the Schools, 41(2), 173-189.

Galyer, K. T., \& Evans, I. M. (2001). Pretend Play and the Development of Emotion Regulation in Preschool Children. Early Child Development and Care, 166(1), 93-108.

Gerstadt, C. L., Hong, Y. J., \& Diamond, A. (1994). The relationship between cognition and action: performance of children 312-7 years old on a stroop- like day-night test. Cognition, 53(2), 129-153.

Gilliom, M., Shaw, D. S., Beck, J. E., Schonberg, M. A., \& Lukon, J. L. (2002). Anger regulation in disadvantaged preschool boys: Strategies, antecedents, and the development of self-control. Developmental Psychology, 38(2), 222-235.

Gross, A. L., \& Ballif, B. (1991). Childrens understanding of emotion from facial expressions and situations: A review. Developmental Review, 11(4), 368-398.

Halberstadt, A. G., Denham, S. A., \& Dunsmore, J. C. (2001). Affective Social Competence. Social development, 10(1), 79-119.

Harris, P. L. (2011). The work of the imagination. Oxford: Blackwell Publ.

Hoffmann, J., \& Russ, S. W. (2012). Pretend play, creativity, and emotion regulation in children. Psychology of Aesthetics, Creativity, and the Arts, 6(2), 175-184.

Howes, C., \& Matheson, C. C. (1992). Sequences in the development of competent play with peers: Social and social pretend play. Developmental Psychology, 28(5), 961-974. 
Hughes, F. P. (1991). Children, play, and development. Needham Heights, MA, US: Allyn \& Bacon.

Hughes, C., \& Dunn, J. (1998). Understanding mind and emotion: Longitudinal associations with mental-state talk between young friends. Developmental Psychology, 34(5), 1026-1037.

Karwowski, M., \& Jankowska, D. M. (2016). Four Faces of Creativity at School. In R. A. Beghetto \& J. C. Kaufman (Eds.), Nurturing Creativity in the Classroom (pp. 337354). Cambridge: Cambridge University Press.

Keane, S. P., \& Calkins, S. D. (2004). Predicting Kindergarten Peer Social Status from Toddler and Preschool Problem Behavior. Journal of Abnormal Child Psychology, 32(4), 409-423.

Krasnor, L. R. (1997). The Nature of Social Competence: A Theoretical Review. Social Development, 6(1), 111-135.

Krasnor, L. R., \& Pepler, D. (1980). The study of children's play: Some suggested future directions. New Directions for Child and Adolescent Development, 9, 85- 95.

Lagattuta, K. H., Wellman, H. M., \& Flavell, J. H. (1997). Preschoolers Understanding of the Link between Thinking and Feeling: Cognitive Cuing and Emotional Change. Child Development, 68(6), 1081-1104.

Lane, J. D., Ronfard, S., Francioli, S. P., \& Harris, P. L. (2016). Children's imagination and belief: Prone to flights of fancy or grounded in reality? Cognition, 152, 127-140.

Lazarus, R. S. (1991) Emotion and adaptation. New York: Oxford University Press.

Leslie, A. M. (1987). Pretense and representation: The origins of "theory of mind.". Psychological Review, 94(4), 412-426.

Levin, D. E., \& Carlsson-Paige, N. (2006). The war play dilemma: What every parent and teacher needs to know (2nd ed.). New York: Teachers College Press.

Li, A. K. (1978). Effects of play on novel responses in kindergarten children. Alberta Journal of Educational Research, 24(1), 31-36.

Lillard, A. (2001). Pretend play as twin earth: A social-cognitive analysis. Developmental Review, 21(4), 495-531.

Lillard, A. S., Lerner, M. D., Hopkins, E. J., Dore, R. A., Smith, E. D., \& Palmquist, C. M. (2013). The impact of pretend play on children's development: A review of the evidence. Psychological Bulletin, 139(1), 1-34.

Lindsey, E. W., \& Colwell, M. J. (2013). Pretend and Physical Play: Links to Preschoolers' Affective Social Competence. Merrill-Palmer Quarterly, 59(3), 330-360. 
Mullineaux, P. Y. \& Dilalla, L. F. (2009). Preschool Pretend Play Behaviors and Early Adolescent Creativity. The Journal of Creative Behavior, 43 (1), 41-57.

Newcomb, A. F., Bukowski, W. M., \& Pattee, L. (1993). Childrens peer relations: A metaanalytic review of popular, rejected, neglected, controversial, and average sociometric status. Psychological Bulletin, 113 (1), 99-128.

Nichols, S. (2004). Imagining and Believing: The Promise of a Single Code. Journal of Aesthetics and Art Criticism, 62 (2), 129-139.

Peter, M. (2003). Drama, narrative and early learning. British Journal of Special Education, 30 (1), 21-27.

Prabhu, V., Sutton, C., \& Sauser, W. (2008). Creativity and Certain Personality Traits: Understanding the Mediating Effect of Intrinsic Motivation. Creativity Research Journal, 20 (1), 53-66.

Root-Bernstein, M. (2014). Inventing imaginary worlds: from childhood play to adult creativity across the arts and sciences. Lanham, MD: Rowman \& Littlefield Education.

Rothbart, M. K., Ahadi, S. A., \& Hershey, K. L. (1993). Temperament and social behavior in childhood. Merrill-Palmer Quarterly, 40 (1), 21-39.

Rubin, K. H., Bukowski, W., \& Parker, J. G. (1998). Peer interactions, relationships, and groups. In W. Damon (Editor-in-Chief) \& N. Eisenberg (Vol. Ed.), Handbook of child psychology: Vol. 3. Social, emotional, and personality development (5th ed., pp. 619-700). New York: Wiley.

Runco, M. (2004). Creativity. Annual Review of Psychology, 55, 657-687.

Russ, S. W. (2014). Pretend Play in Childhood: Foundation of Adult Creativity. Washington: American Psychological Association.

Russ, S. W. (2004). Play in child development and psychotherapy. Mahwah, NJ: Lawrence Erlbaum Associates.

Russ, S. \& Grossman-Mckee, A. (1990). Affective Expression in Childrens Fantasy Play, Primary Process Thinking on the Rorschach, and Divergent Thinking. Journal of Personality Assessment, 54(3), 756-771.

Russ, S. W., Robins, A. L., \& Christiano, B. A. (1999). Pretend Play: Longitudinal Prediction of Creativity and Affect in Fantasy in Children. Creativity Research Journal, 12(2), 129-139.

Russ, S. W., \& Schafer, E. D. (2006). Affect in Fantasy Play, Emotion in Memories, and Divergent Thinking. Creativity Research Journal, 18(3), 347-354.

Saarni, C. (1984). An Observational Study of Childrens Attempts to Monitor Their Expressive Behavior. Child Development, 55(4), 1504-1513. 
Saracho, O. N. (1992). Preschool children's cognitive style and play and implications for creativity. Creativity Research Journal, 5(1), 35-47.

Seja, A. L., \& Russ, S. W. (1999). Childrens fantasy play and emotional understanding. Journal of Clinical Child Psychology, 28(2), 269-277.

Seja-Kaugars, A., \& Russ, S. W. (2009). Assessing Preschool Children's Pretend Play: Preliminary Validation of the Affect in Play Scale-Preschool Version, Early Education and Development, 20(5), 733-755.

Singer, D. G., \& Singer, J. L. (1992). The house of make-believe children's play and the developing imagination. Cambridge: Harvard University Press.

Smilansky, S., \& Shefatya, L. (1990). Facilitating play: a medium for promoting cognitive, socio-emotional, and academic development in young children. Gaithersburg: Psychosocial \& Educational Pub.

Smith, A. (2006). Cognitive Empathy and Emotional Empathy in Human Behavior and Evolution. The Psychological Record, 56(1), 3-21.

Smith, P. K., \& Vollstedt, R. (1985). On Defining Play: An Empirical Study of the Relationship between Play and Various Play Criteria. Child Development, 56(4), 1042-1050.

Swindells, D., \& Stagnitti, K. (2006). Pretend play and parents' view of social competence: The construct validity of the Child-Initiated Pretend Play Assessment. Australian Occupational Therapy Journal, 53(4), 314-324.

Tacher, E. L., \& Readdick, C. A. (2006). The Relation Between Aggression and Creativity Among Second Graders, Creativity Research Journal, 18(3), 261-267.

Taylor, M. (1999). Imaginary companions and the children who create them. New York: Oxford University Press.

Taylor, M. \& Carlson, S. M. (1997). The Relation between Individual Differences in Fantasy and Theory of Mind. Child Development, 68(3), 436-455.

Taylor, M. \& Mottweiler, C. M. (2008). Imaginary Companions: Pretending They Are Real but Knowing They Are Not. American Journal of Play, 1(1). 47-54

Udwin, O. (1983). Imaginative Play Training As An Intervention Method With Institutionalised Preschool Children. British Journal of Educational Psychology, 53(1), 32-39.

Van de Vondervoort, J. W., \& Friedman, O. (2017). Young children protest and correct pretense that contradicts their general knowledge. Cognitive Development, 43, 182-189.

Vygotsky, L. S. (1930/2004). Imagination and creativity in childhood. Journal of Russian and East European Psychology, 42(1), 7-97.

Wallace, C. E., \& Russ, S. W. (2015). Pretend play, divergent thinking, and math achievement in girls: A longitudinal study. Psychology of Aesthetics, Creativity, and the Arts, 9(3), 296-305. 
Weitzman, E., \& Greenberg, J. (2002). Learning Language and Loving It: A guide to promoting children's social, language, and literacy development in early childhood settings. Toronto: The Hanen Centre.

Wellman, H. M., Cross, D., \& Watson, J. (2001). Meta-Analysis of Theory-of-Mind Development: The Truth about False Belief. Child Development, 72(3), 655-684.

Wellman, H. M., Harris, P. L., Banerjee, M., \& Sinclair, A. (1995). Early understanding of emotion: Evidence from natural language. Cognition \& Emotion, 9(2-3), 117-149.

Wimmer, H., \& Perner, J. (1983). Beliefs about beliefs: Representation and constraining function of wrong beliefs in young children's understanding of deception. Cognition, 13(1), 103-128.

Woolley, J. D., \& Lillard, A. S. (2015). Children's cognizing the unreal. Cognitive Development, 34, 1-2.

Yates, T., Ostrosky, M. M., Cheatham, G. A., Fettig, L., Shaffer, A., \& Santos, R. M. (2008). Research synthesis on screening and assessing social-emotional competence. Retrieved from Center on the Social Emotional Foundations for Early Learning: http://csefel.vanderbilt.edu/documents/rs_screening_assessment.pdf

Youngblade, L. M., \& Dunn, J. (1995). Individual Differences in Young Childrens Pretend Play with Mother and Sibling: Links to Relationships and Understanding of Other Peoples Feelings and Beliefs. Child Development, 66(5), 1472-1492.

Corresponding author at: Dorota M. Jankowska, Department of Educational Sciences, The Maria Grzegorzewska Pedagogical University, Szczesliwicka St., 40, 02353 Warsaw, Poland.

E-mail: dorotamariajankowska@gmail.com 